\title{
Lack of Correlation Between the Mean Tender Point Score and Self-Reported Pain in Fibromyalgia
}

\author{
Johannes W. G. Jacobs, Johannes J. Rasker, Agnes van der Heide, Johannes W. Boersma, \\ Alida C. E. de Blécourt, Eduard N. Griep, Martin H. van Rijswijk, and Johannes W. J. Bijlsma
}

Objectives. To study the validity and nature of selfassessed symptoms among patients with fibromyalgia syndrome (FMS) and to compare our data with findings reported in the US. To determine whether tender point scores correlate with self-reported pain and other symptoms and to study the influence of disease duration.

Methods. Tender point scores were assessed in 113 consecutive patients with FMS. All patients completed 2 self-assessment questionnaires (an extended Campbell list, the Enschede Fibromyalgia Questionnaire, and the Dutch Arthritis Impact Measurement Scales).

Results. The self-assessed symptoms of the Dutch FMS patients seem to be valid and are comparable with those of American patients. No association between disease duration and number of self-reported symptoms was found. An association between self-reported pain and mean tender point score was lacking for patients with disease of shorter duration and was weak for patients with disease of longer duration.

Johannes W. G. Jacobs, MD, PhD, Professor Johannes W. J. Bijlsma, $\mathrm{MD}, \mathrm{PhD}$, Rheumatologists, Agnes van der Heide, MD, PhD, Research Fellow, Department of Rheumatology, University Hospital Utrecht; Professor Johannes J. Rasker, MD, $\mathrm{PhD}$, Rheumatologist, Hospital Medisch Spectrum Twente; Johannes W. Boersma, MD, Rheumatologist (retired), Arnhem; Eduard N. Griep, MD, Rheumatologist, Hospital Medisch Centrum Leeuwarden; and Professor Martin H. van Rijswijk, MD, PhD, Rheumatologist, and Alida C. E. de Blécourt, MD, PhD, Rehabilitation Specialist, University Hospital Groningen, The Netherlands.

Address correspondence to Johannes W. G. Jacobs, MD, PhD, University Hospital Utrecht, Department of Rheumatology, F 02.223, P.O. Box 85500, 3508 GA Utrecht, The Netherlands.

Submitted for publication January 19, 1995; accepted in revised form October 6, 1995.

(C) 1996 by the American College of Rheumatology.
Conclusions. The use of a self-report questionnaire for patients with FMS is feasible and appears to be valid. Tender point scores and self-reported pain represent very different aspects of pain in FMS.

Key words. Fibromyalgia; Self-assessment; Tender points; Pain.

\section{INTRODUCTION}

The fibromyalgia syndrome (FMS) is a puzzling nonarticular rheumatic syndrome characterized by chronic, widespread musculoskeletal pain as the most prominent symptom, and marked tenderness to pressure at specific sites on physical examination (1-3). These so-called tender points lie at the insertion of tendons, ligaments, and muscles. There are no signs of joint or soft tissue inflammation, and joint deformity does not develop. In addition to pain, various other (nonspecific) complaints are frequently reported by patients with FMS, such as sleep disturbance, fatigue, paresthesia, anxiety, headache, and morning stiffness (1-7). Clinically, there is a major overlap between FMS and other pain and fatigue syndromes, e.g., chronic fatigue syndrome, irritable bowel syndrome, and tension headache, which suggests that FMS might not be a homogeneous entity (6).

In contrast to rheumatoid arthritis, for which firm correlations between symptoms, e.g., pain and joint scores on physical examination, have been found, there is a lack of correlation between symptoms and tender point scores in FMS $(6,7)$. This might be due to low reliability of the symptoms and/or tender point scores. However, tender point scores seem to be reliable (8). Another possibility, of course, is that tender point 
scores and symptoms are indeed independent, entirely different aspects of FMS. This would be very intriguing with respect to the pathophysiology of FMS.

There is no generally accepted method for the assessment of symptoms in FMS. Since the many nonspecific symptoms of FMS may be subject to major observer interpretation, self-assessment might be the best approach. In some studies, e.g., the investigation resulting in the American College of Rheumatology (ACR) classification criteria, the self-administered questionnaire developed by Campbell et al was used $(2,3)$. This questionnaire is considered to be very useful both clinically and for research purposes (3), although it has not yet been validated.

The aims of the present study were: 1) to investigate whether self-assessment of symptoms by patients with FMS using a Dutch version of the Campbell questionnaire is feasible and valid, 2) to gain insight into the prevalence and nature of symptoms in a series of patients with established FMS in The Netherlands and to compare these data with findings reported in the US, and 3) to study the correlation between tender point scores and self-assessed pain as well as other selfassessed symptoms, and to investigate the influence of disease duration.

\section{PATIENTS AND METHODS}

Patients. Consecutive outpatients with primary FMS visiting 3 rheumatology departments in The Netherlands were asked to participate. In all cases, the diagnosis was established on the basis of the criteria of Yunus (1). To avoid selection bias, no FMS classification criteria were set for inclusion at the start of the study. Since the severity of signs and symptoms may fluctuate in FMS, as in other rheumatic diseases, the use of such inclusion criteria would not have been compatible with our intention that the results of the study be applicable to the population of FMS outpatients visiting Dutch rheumatology departments.

Variables. All patients completed the Enschede Fibromyalgia Questionnaire (EFQ), a Dutch extended version of the self-report Campbell questionnaire (2). The 15 items of this questionnaire were translated; 8 items concerning irritable bowel syndrome, neurologic symptoms, and the (lack of) effect of analgesics were added because they are frequently reported in association with FMS. Thus, the EFQ consists of 17 items about symptoms and complaints and 6 items about factors which can modulate pain and well-being. For each question, there were 4 responses: "never," "sometimes," "often," and "almost always" (Table 1). With regard to the re-
Table 1. Ranked scores for the items of the Enschede Fibromyalgia Questionnaire

\begin{tabular}{lc}
\hline & Yes $(\%)^{*}$ \\
\hline Symptoms & \\
I have pain in my muscles and joints & 96 \\
I tire easily & 93 \\
I have pain in my neck and shoulders & 88 \\
I am stiff in the morning & 85 \\
I ache in the morning & 84 \\
I wake up frequently at night & 73 \\
I have regular bowel movementst & 68 \\
I am too tired during the day to do what I want to do & 68 \\
My hands and feet feel as if they are swollent & 64 \\
Pain wakes me up at night & 62 \\
I have "pins and needles" in my hands and feet & 60 \\
I have headachest & 56 \\
I have anesthetized sensations in my hands and feett & 55 \\
I have abdominal painst & 31 \\
I suffer from flatulence & 25 \\
I sleep well at night & 23 \\
I feel well rested when I get up in the morning & 11 \\
Modulating factors & \\
My pain is affected by the weather & 67 \\
Heat (such as a heating pad) helps my pain & 41 \\
I have more pain when I am emotionally upset & 34 \\
Exercise makes me feel better & 30 \\
Analgesics are effective for my paint & 20 \\
My pain is worsened by noise & 16 \\
\hline * After transformation of "never" and "sometimes" into "no" and "often," \\
and "almost always" into "yes." \\
t The 8 items of the questionnaire that were added to the 15 original items \\
of the Campbell questionnaire.
\end{tabular}

sponses, the period of time to be taken into consideration was not stated, as in the original version.

To assess symptoms not covered by the EFQ, such as health perception, anxiety, and depression, and to get a second self-assessed measure of pain, the Dutch version of the Arthritis Impact Measurements Scales (Dutch AIMS) was also completed; the scores were transformed into scale scores $(9,10)$.

The 14 tender points described by Smythe were assessed by the investigators (JWGJ, JWJB, ACEDB) who used the thumb or the second finger to apply a pressure of approximately $4 \mathrm{~kg} \mathrm{(4).} \mathrm{The} \mathrm{following} \mathrm{scoring} \mathrm{system}$ was used for grading the severity of the resulting pain: $0=$ no pain; 1 = mild pain, no grimace, $2=$ spontaneous verbal reactions to pain, and grimace, and $3=$ severe pain with withdrawal. We had used this scoring system in previous studies of patients with FMS $(8,11,12)$. The reliability of this manual palpation method (mean test-retest and inter-observer generalizability coefficients [Cronbach's $\alpha$ ] of 0.74 and 0.71 , respectively) is equal to that of the pressure algometer (8). For each patient, the mean of the scores for the 14 tender points was calculated, and the number of tender 
Table 2. Characteristics of the 3 patient groups

\begin{tabular}{lcccc}
\hline & All centers & Arnhem & Enschede & Groningen \\
\hline Number of patients & 113 & 31 & 47 & 35 \\
$\quad$ Men & 7 & 2 & 2 & 3 \\
Women & 106 & 29 & 45 & 32 \\
Mean age (SD) & $48(10)$ & $45(9)$ & $50(11)$ & $47(10)$ \\
Mean disease duration in years (SD) & $13(10)$ & $10(9)$ & $15(11)$ & $12(7)$ \\
Range & $0.5-45.0$ & $2.0-35.0$ & $0.5-45.0$ & $5.0-40.0$ \\
$25-75$ percentiles & $6-16$ & $3-15$ & $7-20$ & $8-15$ \\
Mean tender point score (SD)* & $1.4(0.5)$ & $1.8(0.5)$ & $1.3(0.4)$ & $1.3(0.4)$ \\
Range & $0.1-2.9$ & $1.0-2.9$ & $0.4-2.1$ & $0.1-2.1$ \\
$25-75$ percentiles & $1.1-1.8$ & $1.3-2.1$ & $1.0-1.6$ & $1.1-1.6$ \\
Mean number of tender points (SD) & $11(2.8)$ & $13(1.7)$ & $11(2.7)$ & $11(3.3)$ \\
Range & $1-14$ & $9-14$ & $4-14$ & $1-14$ \\
$25-75$ percentiles & $10-14$ & $12-14$ & $9-13$ & $9-13$ \\
Mean number of symptoms (SD)† & $11(3)$ & $12(3)$ & $12(3)$ & $10(3)$ \\
Range & $3-17$ & $7-17$ & $3-17$ & $4-17$ \\
$25-75$ percentiles & $9-14$ & $10-14$ & $10-14$ & $7-12$ \\
\hline
\end{tabular}

* Assessing the 14 tender points according to Smythe. Mean tender point score maximum 3; mean number of tender points maximum 14.

† Number of items on the Enschede Fibromyalgia Questionnaire scored "yes" (after transformation of "never" and "sometimes" into "no" and "often," and "almost always" into "yes"); the 6 modulating factors (see Table

3) were excluded. Maximum 17

points with a score $\geq 1$ (according to the ACR definition of a tender point [3]) was determined.

Methods of analysis. To analyze the prevalence of self-assessed symptoms, the responses on the EFQ were transformed: "never" and "sometimes" became "no," and "often" and "almost always" became "yes," as described previously (3). The prevalence of self-reported symptoms using the EFQ among patients of the 3 Dutch centers was compared. The internal consistency (Cronbach's $\alpha$ ) of the EFQ was investigated by subjecting the original item scores to factor analysis (principal axis factoring and varimax rotation). Items with factor loadings $\geq 0.40$ for only 1 factor were retained. For this analysis, all 6 items on modulating influences and 3 items that had a skewed distribution (absolute skewness $\geq 1$ : pain in muscles/joints, pain in neck/shoulders, and feeling well-rested when getting up in the morning) were excluded.

The prevalence of symptoms among Dutch patients (using data from the EFQ and Dutch AIMS) was compared with that found for American patients with FMS $(1-3,6)$.

Spearman's rank correlation coefficients between self-assessed symptoms and the mean tender point score were determined. The influence of disease duration on the correlation between the mean tender point score and self-assessed pain was investigated; the correlation of the number of tender points with self- assessed pain was determined. To investigate whether the number of symptoms per patient depended on disease duration, the mean number of symptoms was calculated for the groups of patients with a disease duration $<10$ years $(n=54)$ and $\geq 10$ years $(n=59)$. The mean number of symptoms and the disease duration were also tested for a linear or nonlinear association statistically, and visually on a 2-way plot.

For statistical analyses, the computer software packages SPSS/PC+ and Number Cruncher Statistical System were used (13).

\section{RESULTS}

Patient characteristics. The characteristics of the patient groups from the 3 rheumatology departments are shown in Table 2 . There were no statistically significant or clinically relevant differences between the groups. Of the 113 patients, only 7 were male. The mean age was 48 years. The mean number of tender points was 11 (maximum possible 14), the mean number of selfreported symptoms, using the EFQ, was 11 (maximum possible 17), and the mean tender point score was 1.4 (maximum possible 3).

The frequencies of each of the 17 symptoms assessed by the EFQ among the patients from the 3 centers were fairly similar (differences of less than $30 \%$ ), except for the means of 2 medical centers for "waking up at night" 
Table 3. Factor analysis of the scores of the 113 patients for the Enschede Fibromyalgia Questionnaire

\begin{tabular}{lcccc}
\hline & \multicolumn{5}{c}{ Factors and factor loading* } \\
\cline { 2 - 5 } & 1 & 2 & 3 & 4 \\
\hline I sleep well at night & - & -0.74 & - & - \\
I wake up frequently at night & - & 0.70 & - & - \\
Pain wakes me up at night & - & 0.73 & - & - \\
I tire easily & - & - & - & 0.72 \\
I am too tired during the day to do what I want to do & - & - & - & 0.79 \\
I am stiff in the morning & - & - & - & - \\
I ache in the morning & - & - & - & - \\
I have regular bowel movements & - & - & -0.69 & - \\
I have abdominal pains & - & - & 0.74 & - \\
I suffer from flatulence & - & - & 0.60 & - \\
I have headaches & - & - & - & - \\
I have "pins and needlts" in my hands and feet & 0.85 & - & - & - \\
I have anesthetized sensations in my hands and feet & 0.83 & - & - & - \\
My hands and feet feel as if they are swollen & 0.60 & - & - & - \\
Eigenvalue & & & & \\
\% of variance explained & 3.78 & 1.71 & 1.29 & 1.22 \\
Cronbach's $\alpha \dagger$ & 27.0 & 12.2 & 9.2 & 8.7 \\
\hline
\end{tabular}

* Only items with factor loading $\geq 0.40$, loading on just 1 factor. Factor 1 = paresthesia; factor $2=$ sleep disturbance; factor $3=$ irritable bowel syndrome; factor $4=$ fatigue.

+ For the relevant items.

(data not shown). Factor analysis yielded 3 factors consisting of 3 items and 1 factor consisting of 2 items (Table 3). Factor 1, which describes neurologic symptoms, is called "paresthesia," factor 2 "sleep disturbance," factor 3, which describes abdominal symp-

Table 4. Comparison of the prevalence of symptoms (\%) among Dutch patients and other groups of patients with fibromyalgia syndrome*

\begin{tabular}{lccccc}
\hline & \multicolumn{5}{c}{ Study (ref.) } \\
\cline { 2 - 6 } & $\begin{array}{c}\text { Dutch } \\
\text { (present) }\end{array}$ & $\begin{array}{c}\text { Yunus Campbell } \\
(1)\end{array}$ & $\begin{array}{c}\text { ACR } \\
(2)\end{array}$ & $\begin{array}{c}\text { Quimby } \\
(3)\end{array}$ & $(6)$ \\
\hline Morning stiffness & 85 & 72 & 91 & 76 & 86 \\
Fatigue & 83 & 92 & 100 & 78 & 91 \\
Sleep disturbance & 71 & 56 & $68+$ & 76 & 79 \\
Paresthesia & 60 & $58 \neq$ & - & 67 & - \\
Headache & 56 & 44 & 55 & 54 & 63 \\
Anxiety§ & 47 & 70 & - & 45 & 56 \\
Irritable bowel & 29 & 34 & 50 & 36 & 37 \\
\hline
\end{tabular}

* Methods of data collection in the American College of Rheumatology (ACR) investigation were not described in detail (3). In our study (Dutch) for morning stiffness, the Enschede Fibromyalgia Questionnaire (EFQ) item "stiffness in the morning," and for headache, the EFQ item "headaches," were used; for fatigue, sleep disturbance, paresthesia, and irritable bowel syndrome, the mean percentages of the items making up the respective factors (Table 1) were calculated.

+ Waking up frequently.

* Subjective swelling $32 \%$, numbness $26 \%$

$\S$ Anxiety in the Dutch group was defined as a score of $\geq 5$ on the Anxiety scale of the Dutch Arthritis Impact Measurement Scales (range 0-10, where $0=$ no anxiety and $10=$ maximum anxiety) toms, "irritable bowel," and factor 4 "fatigue." The internal consistency of these factors (Cronbach $\alpha$ values) ranged from $0.62-0.71$. For research purposes, a value of $\alpha \geq 0.6$ is considered acceptable for scales (14). Because the value of $\alpha$ increases with the number of items in a scale, the values found in our study for scales consisting of only 2 or 3 items are satisfactory. Three items (stiffness in the morning, aching in the morning, and headaches) were not included in the factors.

The prevalence and nature of symptoms assessed by the EFQ are shown in Table 1; pain, fatigue, and stiffness were the most frequent symptoms. The prevalence of the symptoms among Dutch FMS patients was, in general, comparable to that found in American investigations (Table 4) (1-3), although there were notable differences in the frequency of paresthesia, anxiety, and irritable bowel between individual studies.

The 2 self-reported measures of pain correlated with many other self-reported symptoms (Table 5). This indicates that patients who reported severe pain also experienced other signs and symptoms as being of a severe intensity. The mean tender point score only exhibited a statistically significant correlation with the 2 self-reported measures of pain and sleep disturbance, the coefficients being $0.22,0.20$, and 0.19 , respectively. The correlation coefficient for the mean tender point score and self-reported pain (Dutch AIMS) was 0.03 ( $P$ not significant) for patients with disease of less than 
Table 5. Correlations of self-assessed symptoms with mean tender point scores for patients with fibromyalgia syndrome*

\begin{tabular}{|c|c|c|c|c|c|c|c|c|c|c|}
\hline & 2 & 3 & 4 & 5 & 6 & 7 & 8 & 9 & 10 & $\begin{array}{c}\text { Mean } \\
\text { tender } \\
\text { point } \\
\text { score }\end{array}$ \\
\hline 1. Pain on the Dutch AIMSt & 0.50 & 0.58 & 0.31 & 0.24 & 0.42 & 0.35 & 0.40 & 0.53 & - & 0.22 \\
\hline 2. Pain on the EFQ $\ddagger$ & & 0.35 & 0.23 & - & - & 0.39 & 0.33 & 0.35 & - & 0.20 \\
\hline 3. Arthritis impact $t$ & & & 0.37 & 一 & 0.39 & 0.34 & 0.32 & 0.41 & - & - \\
\hline 4. Health perceptiont & & & & 0.39 & 0.43 & 0.21 & 0.21 & 0.20 & - & - \\
\hline 5. Anxietyt & & & & & 0.72 & 0.25 & - & - & - & - \\
\hline 6. Depressiont & & & & & & 0.42 & 0.22 & 0.34 & 0.27 & - \\
\hline 7. Fatigue & & & & & & & 0.26 & 0.24 & 0.22 & - \\
\hline 8. Paresthesia§ & & & & & & & & 0.36 & 0.22 & - \\
\hline 9. Sleep disturbance§ & & & & & & & & & 0.24 & 0.19 \\
\hline 10. Irritable bowel§ & & & & & & & & & & - \\
\hline
\end{tabular}

* Horizontal item numbers correspond to vertical item numbers. Mean tender point score represents 14 tender points. Spearman's $\rho$ coefficients: all values statistically significant: $0.19-0.24, P$ between 0.05 and $0.01 ; 0.25-0.26, P$ between 0.01 and $0.005 ; 0.27-0.32, P$ between 0.005 and $0.001 ;$ and $>0.32, P<0.001$. † AIMS = Arthritis Impact Measurement Scales, data from scales of Dutch AIMS.

\$ The item "pain in muscles/joints" of the Enschede Fibromyalgia Questionnaire (EFQ).

$\$$ Scales of the EFQ, resulting from factor analysis.

10 years' duration and $0.44(P=0.0006)$ for patients with disease lasting $\geq 10$ years (Figure 1). Therefore, $19 \%$ of the variance of the mean tender point score is explained by self-reported pain in the group with disease of $\geq 10$ years' duration, whereas self-reported pain does not explain any of the variance in the mean tender point score for patients with disease of $<10$ years' duration. Ten years was chosen as the cut-off point because it was the median disease duration in the study. Other cut-off points $(3,4$, and 5 years) were also tested. In these analyses, the correlation between the mean tender point score and self-reported pain remained roughly the same, e.g., $R_{s}=0.24,0.26$, and 0.28 , respectively, for a disease duration of $\geq 3,4$, and 5 years $(P=0.01,0.01$, and 0.009$)$ and $\mathrm{R}_{\mathrm{s}}=-0.03,-0.06$, and -0.02 for disease duration of $<3,4$, and 5 years $(P=$ $0.92,0.81$, and 0.91 ). The correlation coefficient for the number of tender points with self-assessed pain (Dutch AIMS) was $0.27(P<0.01)$.

For patients with a disease duration $<10$ years ( $\mathrm{n}=$ 54), the mean number of symptoms was 11 , the same as for patients with a disease duration of $\geq 10$ years ( $n=$ 59). No linear or nonlinear association between disease duration and number of symptoms could be detected statistically or visually on the 2-way plot (not shown).

\section{DISCUSSION}

The prevalence and nature of self-reported symptoms among patients of 3 Dutch centers were comparable and, in general, were similar to those found for American patients (1-3). This demonstrates that patients are able to complete the EFQ self-report questionnaire and that the results are consistent (14). This, together with the results of factor analysis, indicates that the self-reported items are valid; however, many more aspects of validity of the EFQ are yet to be investigated.

The prevalence of Dutch self-reported symptoms corresponds best to the prevalence of symptoms reported in the ACR study (Table 4). In both studies, FMS classification criteria were not set for inclusion; the samples of patients were clinical ones. Also in both studies, the Campbell questionnaire was applied. This implies that both the study population and the method of assessment are probable causes of differences in the prevalence of symptoms between the reported studies in Table 4 . This underscores the need for a generally accepted instrument to assess the symptoms in FMS, and our findings do not necessarily apply to a research sample in which the ACR classification criteria are used for inclusion.

In our study, there was a lack of correlation between self-assessed symptoms and the mean tender point score (Table 5). This is in agreement with the study by Quimby et al (6), who found that none of the symptoms of Yunus' minor criteria of FMS correlated with the number of tender points for patients with generalized nonarticular rheumatism. The lack of correlation between the 2 self-reported measures of pain and mean tender point score in our study is particularly remarkable. It does not seem likely that this is attributed to our having assessed the 14 tender points according to Smythe instead of the 18 tender points of the ACR criteria, because most of these tender points are the same, or to the fact that 14 tender points were used whereas there are so many more potential tender points in the human body. This lack of correlation between self-reported pain and mean tender point score is con- 
A: Patients with disease duration of $<10$ years $\left(n=54, r_{3}=0.03, p=0.82\right)$ :

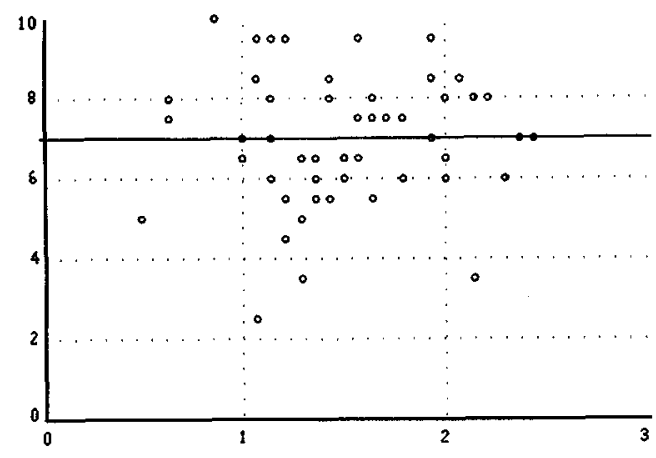

B: Patients with disease duration of $\geq 10$ years $\left(n=59, r_{1}=0.44, p=0.0006\right)$ :

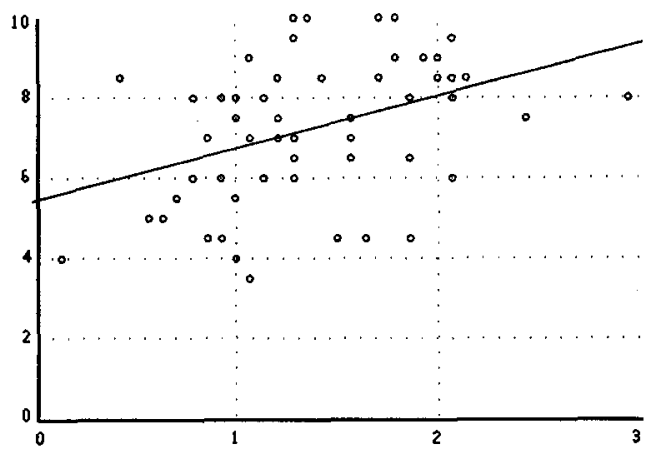

Figure 1. Self-reported pain (y-axis) plotted against mean tender point score ( $\mathrm{x}$-axis). Mean tender point score $=$ the mean of 14 tender points, ranging from 0 (no pain) to 3 (maximum pain). Pain = the self-report scale "Pain" of the Dutch Arthritis Impact Measurement Scales, ranging from 0 (no pain) to 10 (maximum pain). Each dot on the plots represents one patient; the lines are the least square regression lines. For all 113 patients, $R_{s}$ between self-reported pain scores and mean tender point score was 0.22 .

sistent with the observation that physical exercise resulted in increased pain, whereas the number of tender points hardly increased (15). Burckhardt et al also found no correlation between self-reported pain, as assessed by the Fibrositis Impact Questionnaire, and the number of tender points in 25 FMS patients (7). Wolfe et al reported that in a sample from the general population, self-reported pain was also not associated with tender point counts (16). In another investigation involving the general population, it was found that tender point counts were associated with measures of depression, fatigue, and poor sleep, independent of the pain status (17). It may be concluded that tender point scores and self-reported pain represent very different aspects of pain.
This is intriguing with respect to the pathophysiology of FMS and the origin of pain in this syndrome. Although injections of a local anesthetic into tender points have been shown to provide relief of local pain (18), supporting the theory that it may result from repetitive strain or metabolic disorders of the muscles $(19,20)$, studies of muscles and tender point sites by means of biopsies and other techniques have not revealed specific abnormalities (19-24). It seems more likely that signal misinterpretation, neuroendocrine disorders, secondary hyperalgesia, and aberrant central pain mechanisms and pain memory are the keys to the etiology of FMS $(15,25-31)$. This may explain why tricyclic antidepressants-in contrast to nonsteroidal antiinflammatory drugs-may provide (moderate) relief of pain $(18,19,31,32)$, why electroacupuncture is effective, and why conflicting results are reported for the effect of muscle relaxants $(33,34)$. It must be noted, however, that at this time, these "centrally oriented" hypotheses are mainly speculative and that there are findings which are not compatible with these theories, e.g., the altered interleukin secretion in FMS (35). Further research into the effectiveness of different therapeutic strategies might improve our understanding of the pathogenetic mechanisms of FMS.

It is remarkable that in our series, patients with FMS of shorter duration did not exhibit a correlation between self-reported pain and the mean tender point score, in contrast to patients with disease of longer duration. The a priori hypothesis that in FMS of shorter duration, there might possibly be a correlation between self-reported pain and tender point score that is lost with progression of the disease as pain behavior further develops does not hold. The finding cannot be easily explained. However, to investigate the relationship between signs and symptoms and disease duration more properly, prospective, longitudinal, long-term investigations are needed.

The self-reported symptoms of patients with FMS can be used in experimental and clinical situations. The prevalence of the symptoms were comparable to those reported in the literature. The expectation that FMS patients with a high mean tender point score would also have a high pain score and vice versa was not confirmed. It is recommended that for pain measurement in patients with FMS in experimental and clinical situations, both tender points and self-reported pain should be assessed, since they represent quite different aspects of pain.

We thank Professor F. W. Kraaimaat, PhD, and R. Geenen, PhD, Psychologists (Department of Psychology, University Hospital Utrecht), and E. Taal, PhD, Psychologist (Department of Psychology, University Twente, Enschede) for their advice. 


\section{REFERENCES}

1. Yunus M, Masi AT, Calabro JJ, Miller KA, Feigenbaum SL: Primary fibromyalgia (fibrositis): clinical study of 50 patients with matched normal controls. Semin Arthritis Rheum 11:151-171, 1981

2. Campbell SM, Clark S, Tindall EA, Forehand ME, Bennett RM: Clinical characteristics of fibrositis. I. A "blinded," controlled study of symptoms and tender points. Arthritis Rheum 26:817-824, 1983

3. Wolfe F, Smythe HA, Yunus MB, Bennett RM, et al: The American College of Rheumatology 1990 criteria for the classification of fibromyalgia: report of the Multicenter Criteria Committee. Arthritis Rheum 33:160-172, 1990

4. Smythe H: "Fibrositis" and other diffuse musculoskeletal syndromes. In, Textbook of Rheumatology. Second edition. Edited by WN Kelley, ED Harris Jr, S Ruddy, CB Sledge. Philadelphia, WB Saunders, 1985

5. Simms RW, Goldenberg DL: Symptoms mimicking neurologic disorders in fibromyalgia syndrome. J Rheumatol 15:1271-1273, 1988

6. Quimby LG, Block SR, Gratwick GM: Fibromyalgia: generalized pain intolerance and manifold symptom reporting. J Rheumatol 15:1264-1270, 1988

7. Burckhardt CS, Clark SR, Bennet RM: The Fibromyalgia Impact Questionnaire: development and validation. J Rheumatol 18:728-733, 1991

8. Jacobs JWG, Geenen R, van der Heide A, Rasker JJ, Bijlsma JWJ: Are tender point scores by manual palpation reliable? An investigation into the variance of tender point scores. Scand J Rheumatol 24:243-247, 1995

9. Taal E, Jacobs JW, Seydel ER, Wiegman O, Rasker JJ: Evaluation of the Dutch Arthritis Impact Measurement Scales (Dutch-AIMS) in patients with rheumatoid arthritis. Br J Rheumatol 28:487-491, 1989

10. Jacobs JWG, Oosterveld FGJ, Deuxbouts N, et al: Rheumatoid arthritis patients' opinions about their own functional capacity: how valid is it? Ann Rheum Dis 51: 765-768, 1992

11. Jacobs JWG, Rasker JJ, van Riel PLCM, Gribnau FWJ, van de Putte LBA: Behandeling met Rheumajecta en Vasolastine van primaire fibromyalgie: resultaten van een gerandomiseerd, placebo-gecontroleerd, dubbelblind onderzoek. Ned Tijdschr Geneeskd 134:693697,1990

12. Rasker JJ, Jacobs JWG: Fibromyalgia, difficulties in assessing effect of therapy. Clin Exp Rheumatol 5 (suppl): P311, 1987

13. Norušis, MJ: SPSS/PC+ V2.0 Base Manual. Chicago, SPSS Inc., 1988

14. Nunnally JC: Psychometric Theory. Second Edition. New York, McGraw Hill, 1978

15. Van Denderen JC, Boersma JW, Zeinstra P, Hollander AP, van Neerbos BR: Physiological effects of exhaustive physical exercise in primary fibromyalgia syndrome (PFS): is PFS a disorder of neuroendocrine reactivity? Scand J Rheumatol 21:35-37, 1992

16. Wolfe F, Ross K, Anderson J: Tenderness, pain thresh- old, and their correlates in the general population (abstract). Arthritis Rheum 36 (suppl 9):\$220, 1993

17. Croft P, Schollum J, Silman A: Population study of tender point counts and pain as evidence of fibromyalgia. BMJ 309:696-699, 1994

18. Masi AT, Yunus MB: Fibromyalgia-which is the best treatment? A personalized, comprehensive, ambulatory, patient-involved management programme. Baillieres Clin Rheumatol 4:333-370, 1990

19. Bennett RM: Beyond fibromyalgia: ideas on etiology and treatment. J Rheumatol Suppl 19:185-191, 1989

20. Bengtsson A, Henriksson KG, Larsson J: Reduced highenergy phosphate levels in the painful muscles of patients with primary fibromyalgia. Arthritis Rheum 29: 817-821, 1986

21. Von Miehlke K, Schulze G, Eger W: Klinische und experimentelle untersuchungen zum fibrositissyndroom. Z Rheumaforsch 19:310-333, 1960

22. Bartels EM, Danneskiold-Samsøe B: Histological abnormalities in muscle from patients with certain types of fibrositis. Lancet i:755-757, 1986

23. Caro XJ: Immunofluorescent studies of skin in primary fibrositis syndrome. Am J Med 81 (suppl 3A):4349, 1986

24. Yunus MB, Kalyan-Raman UP, Kalyan-Raman K, Masi AT: Pathologic changes in muscle in primary fibromyalgia syndrome. Am J Med 81 (suppl 3A):3842, 1986

25. Harvey AR: Neurophysiology of rheumatic pain. J Orthop Rheumatol 3:187-194, 1990

26. Harvey AR: A neurogenic model for soft-tissue rheumatism and its implications for management. J Orthop Rheumatol 3:231-242, 1990

27. Yunus MB: Towards a model of pathophysiology of fibromyalgia: aberrant central pain mechanisms with peripheral modulation. J Rheumatol 19:846-850, 1992

28. Neeck G, Riedel W: Thyroid function in patients with fibromyalgia syndrome. J Rheumatol 19:1120-1122, 1992

29. Griep EN, Boersma JW, de Kloet ER: Altered reactivity of the hypothalamic-pituitary-adrenal axis in the primary fibromyalgia syndrome. J Rheumatol 20:469-474, 1993

30. Cohen ML, Quintner JL: Fibromyalgia syndrome, a problem of tautology. Lancet 342:906-909, 1993

31. Jacobs JWG, Rasker JJ, Griep EN: Fibromyalgia: a stress related, neuroendocrine disorder? A hypothetical framework on the aetiology and perseverance of the syndrome. Rheumatol Eur 24 (suppl 2):274-276, 1995

32. Bennett RM, Gatter RA, Campbell SM, Andrews RP, Clark SR, Scarola JA: A comparison of cyclobenzaprine and placebo in the management of fibrositis: a double-blind controlled study. Arthritis Rheum 31:1535-1542, 1988

33. Pattrick M, Swannell A, Doherty M: Chlormezanone in primary fibromyalgia syndrome: a double blind placebo controlled study. Br J Rheumatol 32:55-58, 1993

34. Deluze C, Bosia L, Zirbs A, Chantraine A, Vischer TL: Electroacupuncture in fibromyalgia: results of a controlled trial. BMJ 305:1249-1252, 1992

35. Hader N, Rimon D, Kinarty A, Lahat N: Altered interleukin-2 secretion in patients with primary fibromyalgia syndrome. Arthritis Rheum 34:866-872, 1991 